\title{
Spinocerebellar ataxia type 36
}

INSERM

\section{Source}

INSERM. (1999). Orphanet: an online rare disease and orphan drug data base.

Spinocerebellar ataxia type 36. ORPHA:276198

Spinocerebellar ataxia type 36 (SCA36) is a subtype of autosomal dominant cerebellar ataxia type 1 (ADCA type 1; see this term) characterized by gait and limb ataxia, lower limb spasticity, dysarthria, muscle fasiculations, tongue atrophy and hyperreflexia. 